\title{
Brief Report \\ Establishing a Resource to Assess Musculoskeletal Health in Older Adults in the Post-COVID-19 Era: Time to SaLSA?
}

\author{
Faidra Laskou 1,2,*(D), Alexander Linfield ${ }^{1}$, Pritti Aggarwal ${ }^{3,4}$, Elaine M. Dennison ${ }^{1,5}$ and Harnish P. Patel ${ }^{1,2,6}{ }^{\mathbb{D}}$ \\ 1 Medical Research Council Lifecourse Epidemiology Centre, University of Southampton, \\ Southampton SO16 6YD, UK; al2g19@soton.ac.uk (A.L.); emd@mrc.soton.ac.uk (E.M.D.); \\ hp@mrc.soton.ac.uk (H.P.P.) \\ 2 NIHR Southampton Biomedical Research Centre, University of Southampton and University Hospitals \\ Southampton NHS Foundation Trust, Southampton SO16 6YD, UK \\ 3 Living Well GP Partnership, Southampton SO19 9GH, UK; prittiaggarwal@nhs.net \\ 4 School of Primary Care, Population Sciences and Medical Education, University of Southampton, \\ Southampton SO17 1BJ, UK \\ 5 School of Biological Sciences, Victoria University of Wellington, Wellington 6012, New Zealand \\ 6 Medicine for Older People, University Hospital Southampton, Southampton SO16 6YD, UK \\ * Correspondence: faidra.laskou@soton.ac.uk
}

check for

updates

Citation: Laskou, F.; Linfield, A.; Aggarwal, P.; Dennison, E.M.; Patel, H.P. Establishing a Resource to Assess Musculoskeletal Health in Older Adults in the Post-COVID-19 Era: Time to SaLSA? Osteology 2022, 2, 41-51. https://doi.org/10.3390/ osteology2010005

Academic Editor: Umile Giuseppe Longo

Received: 23 November 2021

Accepted: 23 February 2022

Published: 28 February 2022

Publisher's Note: MDPI stays neutral with regard to jurisdictional claims in published maps and institutional affiliations.

Copyright: () 2022 by the authors. Licensee MDPI, Basel, Switzerland. This article is an open access article distributed under the terms and conditions of the Creative Commons Attribution (CC BY) license (https:/ / creativecommons.org/licenses/by/ $4.0 /)$.

\begin{abstract}
Sarcopenia and osteoporosis are associated with morbidity and mortality. The development and progression of these two interrelated conditions are related to genetic and lifestyle factors, including nutrition and physical activity. Restrictions placed on individuals due to the COVID-19 pandemic and infection have led to widespread lifestyle modifications, with data suggesting a negative impact on physical activity levels. There is an urgent need to understand the effect of the pandemic on musculoskeletal health in older adults, at a time when COVID-19 infection and restrictions remain a barrier to research studies. We tested the feasibility of recruiting local community-dwelling older people to establish a new cohort investigating musculoskeletal health-the Southampton Longitudinal Study of Ageing (SaLSA). We invited 1993 community-dwelling older adults registered at the Living Well GP partnership in Southampton, UK, to participate in a study. Questionnaires were completed by participants on health, lifestyle, medication use, comorbidities, physical activity, nutrition, sarcopenia, osteoporosis, and quality of life. Permission was sought for future contact. Descriptive statistics were used on the initial pilot of 175 returned questionnaire data. The median age of participants was 80.4 years in both sexes, 81.3 years (77.9-84) in females, and 81.1 years in males (77.3-83.6). The majority ( $\mathrm{N}=168 / 171,98 \%$ ) of participants were of white Caucasian background; 36/53 (68\%) female participants and 38/119 (32\%) male participants lived alone. Over 80\% (295/353) consented to be contacted for future studies. Recruitment of participants from a primary care practice into a research study was feasible. The next steps are to perform detailed musculoskeletal phenotyping through physical performance measures, grip strength dynamometry, DXA scanning, high-resolution peripheral quantitative computed tomography (HRpQCT), thigh ultrasound, and muscle biopsy, in a subset of participants. Our vision for SaLSA is to build a platform for discovery science and mechanistic studies, with the goal of improving the health care of older people.
\end{abstract}

Keywords: older adults; musculoskeletal health; sarcopenia; osteoporosis; ageing; COVID-19; longitudinal cohort study

\section{Introduction}

Musculoskeletal health disorders, including osteoporosis and sarcopenia, are highly prevalent in older adults, and are associated with a very significant public health burden. Osteoporosis, a disease characterised by low bone mass and structural deterioration of bone tissue, is the most common chronic metabolic bone disease, and contributes to 8.9 million fractures worldwide on an annual basis [1]. Osteoporosis incurred an estimated GBP 
1.8 billion in UK health costs in 2000; this is predicted to increase to GBP 2.2 billion by 2025 [2]. Sarcopenia is characterised by progressive and generalised decline in muscle strength, function, and mass with age, or secondary to disease [3]; it is associated with a range of adverse physical and metabolic outcomes in terms of disability, morbidity, impaired quality of life, and mortality [4], and has also been identified as a predictor of fracture risk [5]. In terms of cost, sarcopenia incurred an estimated USD 18.5 billion in health care costs to the USA in 2000. In the UK, the annual excess cost associated with muscle weakness was estimated to be GBP 2.5 billion [6,7]. Several varying definitions of sarcopenia have contributed to differences in prevalence estimates worldwide, ranging from 3 to 30\% [4,8-10]. Currently, a global consensus on the definition of sarcopenia does not exist, but there are well-constructed diagnostic algorithms that provide a mechanism for clinical case identification [4].

Lifestyle factors such as levels of physical activity, nutrition, alcohol, and smoking have been shown to have effects on both bone and muscle. Physical activity is a very important contributor to bone and muscle health in later life [11]. Along with advancing age, physical inactivity is a major risk factor for both osteoporosis and sarcopenia. Furthermore, specific nutrients affect both bone and muscle-including vitamin D, calcium, vitamin K, and protein - and are critical to musculoskeletal health in later life [12-14].

The COVID-19 pandemic has led to widespread changes in lifestyle globally, as "stay at home" guidance was widely invoked. Older adults-the group most vulnerable to severe disease-were commonly asked to shield, or voluntarily severely restricted their activities. In a recent work, we evaluated how the first wave of the pandemic affected older adults in a pilot study (Nutrition and Physical Activity Study (NAPA)) conducted in the Hertfordshire Cohort Study (HCS) [15]. In total, 71 eligible Caucasian, community-dwelling participants39 male and 32 female, with a mean age (SD) of 83.6 (2.5) years-were surveyed. In this modest sample, more than half $(52 \%)$ of respondents reported being less physically active than before the pandemic. A number of variants of the SARS-CoV-2 virus have been identified, with rolling restrictions remaining in many countries. Widespread vaccination has provided reassurance to many older adults, but many are still fearful of engaging in activities that they previously would have enjoyed [16]. Changes in lifestyle might be expected to have effects on both muscle and bone health, with studies of older adults now required to study these in depth. Given the burden of musculoskeletal disease in late adulthood, research in this group is crucial. Although the rationale for studying this age group is hence clear, the feasibility of establishing a cohort of octogenarians living in their own homes in a global pandemic is untested. We have provided our own experience of recruitment in order to (a) highlight the need to consider these issues in older adults, and (b) advertise the study to invite collaboration early in the study process. Specifically, this study represents a research partnership across the primary-secondary care interface that is unusual in the UK, and might be replicated elsewhere. Here, we report our experience of this, before describing the methodology of the study that is planned.

\section{Materials and Methods}

Study Design

In July 2021 we identified all patients over the age of 75 who were registered at a large GP partnership in Southampton, UK (Living Well Partnership (LWP), https:/ / livingwellpartnership.nhs.uk). Eligibility to participate in the study was decided by their primary care physician. Our sole inclusion criterion was the age of participants ( $>75$ years of age) at the time of recruitment, as we aim to consider musculoskeletal health in this specific age group. Our exclusion criteria included the following:

- Patients with safeguarding issues;

- Patients with mental health and capacity issues;

- Patients with dementia or who were unable to provide consent;

- Patients with learning disabilities;

- Patients in end-of-life care; 
- Patients who are permanently bedbound;

- Patients in residential or nursing homes.

All eligible participants were sent a study pack from LWP, consisting of a participant information sheet (PIS), two copies of a consent form, a questionnaire, and the contact details form.

Initial searches of the Egton Medical Information Systems (EMIS) database identified 2523 registered patients over the age of 75 years from any sex and ethnic group. Of those 2523 patients, 1993 (78\%) were deemed eligible to participate in the study by their primary care physician (Figure 1).

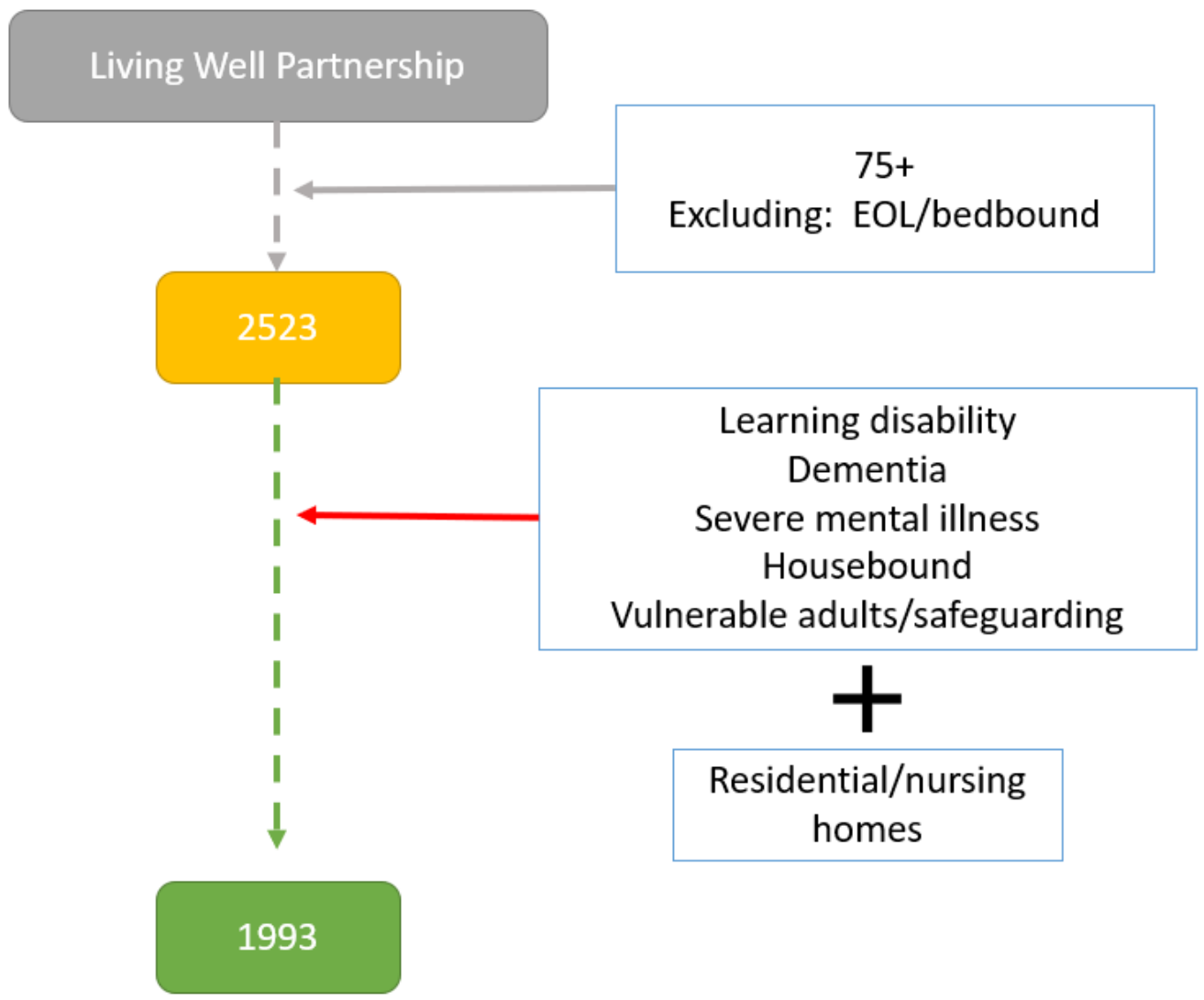

Figure 1. Flowchart of selection of eligible participants (EOL: end of life).

In total, 1993 participants were invited to participate in the study via postal invitation only. Participants indicated their willingness to be involved in the study and returned the copy of the signed consent form, along with the completed questionnaire and the contact details form to the research team at the MRC Lifecourse Epidemiology Centre (MRC LEC) Southampton, using a prepaid envelope. Participants had the opportunity to contact the research team using a dedicated research mobile phone and/or email that was provided for further queries. The returned documents were reviewed by a research team member in order to ensure the validity of those documents, and to identify any missing information. An anonymised ID number was allocated to each participant after ensuring that consent was obtained. A research team member contacted those participants who did not fully complete the consent or contact details forms via email, phone, or in writing.

Invitations were sent out in batches to manage workflow, as researchers were still largely working from home. Phase 1 led to the return of 175 complete questionnaires (Table 1). The questionnaire participants completed, included information on household, lifestyle factors, comorbidities, medical history, physical activity and capability, level of frailty, nutrition, self-reported walking speed, quality of life, and wellbeing. Where available, questions were sourced from validated questionnaires [17-22] (Table 2). Self- 
reported walking speed has been shown to be a good marker of measured walking speed, and has previously been validated in the Hertfordshire Cohort Study [21]. The remaining questionnaires used in the study have previously been used in the HCS, which was also conducted by the MRC LEC Southampton [23].

Table 1. Preliminary baseline characteristics of participants in SaLSA (Southampton Longitudinal Study of Ageing).

\begin{tabular}{|c|c|c|c|c|c|c|c|c|}
\hline \multirow[t]{2}{*}{ Characteristic } & \multicolumn{4}{|c|}{ Female } & \multicolumn{4}{|c|}{ Male } \\
\hline & $\mathbf{N}$ & Median & IQR & $\%$ & $\mathbf{N}$ & Median & IQR & $\%$ \\
\hline Age & 53 & 80.53 & $77-84$ & & 119 & 80.4 & $77-83$ & \\
\hline Number of medications & 53 & 5 & $3-7.75$ & & 117 & 4 & $3-7$ & \\
\hline Polypharmacy $(>=5)$ & 33 & & & 62.2 & 22 & & & 18.8 \\
\hline Number of comorbidities & 53 & 3 & $2-4$ & & 119 & 3 & $1-3$ & \\
\hline \multirow[t]{2}{*}{ Multimorbidity $(>=2)$} & 22 & & & 82 & 86 & & & 71 \\
\hline & $\mathrm{N}$ & $\mathrm{N}$ & & $\%$ & $\mathrm{~N}$ & $\mathrm{~N}$ & & $\%$ \\
\hline Ethnic group & 53 & & & & 118 & & & \\
\hline White & & 50 & & 94 & & 118 & & 100 \\
\hline Indian & & 2 & & 4 & & 0 & & 0 \\
\hline Black Caribbean & & 1 & & 2 & & 0 & & 0 \\
\hline Marital status & 53 & & & & 119 & & & \\
\hline Alone & & 36 & & 68 & & 38 & & 32 \\
\hline Not alone (lives with friend/partner/family) & & 17 & & 32 & & 81 & & 68 \\
\hline Age leaving school & 52 & & & & 119 & & & \\
\hline$<=14$ & & 2 & & 4 & & 17 & & 14 \\
\hline$>14$ & & 50 & & 96 & & 102 & & 86 \\
\hline Education after school & 52 & & & & 119 & & & \\
\hline None & & 24 & & 46.1 & & 33 & & 27.7 \\
\hline Apprenticeship & & 7 & & 13.4 & & 47 & & 39.4 \\
\hline Part-time college & & 8 & & 15.3 & & 45 & & 37.8 \\
\hline Full-time college & & 8 & & 15.3 & & 15 & & 12.6 \\
\hline Other & & 9 & & 17.3 & & 12 & & 10 \\
\hline \multicolumn{9}{|l|}{ Higher qualifications } \\
\hline None & & 22 & & 40 & & 41 & & 34 \\
\hline O levels & & 23 & & 42 & & 48 & & 40 \\
\hline A levels & & 10 & & 18 & & 20 & & 17 \\
\hline Vocational training certificate & & 12 & & 22 & & 42 & & 35 \\
\hline University degree & & 1 & & 2 & & 20 & & 17 \\
\hline Higher professional qualifications & & 7 & & 13 & & 13 & & 11 \\
\hline Smoking status & 53 & & & & 118 & & & \\
\hline Ex-smoker & & 20 & & 71.6 & & 78 & & 66 \\
\hline Current smoker & & 0 & & 0 & & 5 & & 3.38 \\
\hline Alcohol & 54 & & & & 121 & & & \\
\hline More than recommended units/week (14) & & 1 & & 1.85 & & 25 & & 20.6 \\
\hline COVID-19 infection & 50 & & & & 117 & & & \\
\hline Yes & & 0 & & 0 & & 4 & & 3.41 \\
\hline No & & 48 & & 96 & & 111 & & 95 \\
\hline Suspected but not confirmed & & 2 & & 4 & & 2 & & 1.7 \\
\hline Self-reported walking speed & 54 & & & & 121 & & & \\
\hline Fast & & 2 & & 4 & & 1 & & 1 \\
\hline Fairly brisk & & 8 & & 15 & & 22 & & 18 \\
\hline Normal speed & & 13 & & 24 & & 40 & & 33 \\
\hline Stroll at an easy pace & & 15 & & 28 & & 34 & & 28 \\
\hline Very slow & & 15 & & 28 & & 23 & & 19 \\
\hline Unable to walk & & 1 & & 2 & & 1 & & 1 \\
\hline & $\mathrm{N}$ & $\mathrm{N}$ & & $\%$ & $\mathrm{~N}$ & $\mathrm{~N}$ & & $\%$ \\
\hline Falls past year & 52 & & & & 114 & & & \\
\hline$>=1$ fall & 17 & & & 32.6 & 28 & & & 24.5 \\
\hline
\end{tabular}


Table 1. Cont.

\begin{tabular}{|c|c|c|c|c|c|c|c|c|}
\hline \multirow[t]{2}{*}{ Characteristic } & \multicolumn{4}{|c|}{ Female } & \multicolumn{4}{|c|}{ Male } \\
\hline & $\mathbf{N}$ & Median & IQR & $\%$ & $\mathbf{N}$ & Median & IQR & $\%$ \\
\hline Fracture since age 45 & 52 & & & & 112 & & & \\
\hline Yes & & 19 & & 36.5 & & 15 & & 31.25 \\
\hline No & & 33 & & 67 & & 97 & & 87 \\
\hline Self-rated health (SF-36) & 53 & & & & 120 & & & \\
\hline Excellent & & 3 & & 5.66 & & 4 & & 3.33 \\
\hline Very good & & 13 & & 24.5 & & 27 & & 22.5 \\
\hline Good & & 19 & & 35.8 & & 51 & & 42.5 \\
\hline Fair & & 17 & & 32 & & 32 & & 26.6 \\
\hline Poor & & 1 & & 1.88 & & 6 & & 5 \\
\hline
\end{tabular}

Table 2. List of subsections of questionnaires and data collected.

\begin{tabular}{c} 
Questionnaires \\
\hline Living circumstances and lifestyle factors \\
COVID-19 questionnaire \\
Medical conditions and medication history \\
Physical activity scale for the elderly (PASE) \\
Self-reported walking speed \\
Bone health questionnaire \\
Fried frailty questionnaire \\
Sarcopenia questionnaire (SARC-F) \\
Quality of life questionnaire (SF-36) \\
DETERMINE checklist \\
Food frequency questionnaire (FFQ)
\end{tabular}

In the planned next phases of the study, participants will be invited to attend a faceto-face clinic visit, where anthropometry, grip strength, gait speed, appendicular lean mass, and bone mineral density will be measured. Ultrasound scans, as a new screening method to diagnose sarcopenia, will also be performed [24]. Standardised effect sizes for objectively measured physical activity in relation to grip strength, walking speed, and appendicular mass index were estimated as $0.11,0.26$, and 0.15 , respectively, in a cohort of a similar age [25]. The sample sizes required to detect these effect sizes with $80 \%$ power and a 5\% significance level are 651 for grip strength, 119 for walking speed, and 351 for appendicular lean mass index; Statistics Kingdom was used for these calculations [26]. A subset of patients who are willing and have given consent will also undergo a highresolution $\mathrm{PQCT}$ scan, before undergoing a percutaneous muscle biopsy of the vastus lateralis [27]. Outcome measures for SaLSA are summarised in Table 3.

Table 3. Overview of the measures to be collected during the 1st and 2nd phases of the study.

\begin{tabular}{|c|c|c|c|c|}
\hline Variables & Instrument/Scale & Type of Assessment & 1st Phase & 2nd Phase \\
\hline Age & Calculated based on the date of birth given & Questionnaire & $\sqrt{ }$ & \\
\hline Sex & Female or male stated & Questionnaire & $\sqrt{ }$ & \\
\hline Ethnicity & As self-reported & Questionnaire & $\sqrt{ }$ & \\
\hline Marital status & Self-reported marital status & Questionnaire & $\sqrt{ }$ & \\
\hline \multirow{2}{*}{ Education } & \multirow{2}{*}{$\begin{array}{l}\text { Age of leaving school } \\
\text { Self-reported education after school and/or } \\
\text { higher qualifications }\end{array}$} & Questionnaire & $\sqrt{ }$ & \\
\hline & & Questionnaire & & \\
\hline Living arrangements & $\begin{array}{c}\text { Self-reported: own property/rented } \\
\text { accommodation/residential home/nursing } \\
\text { home/other }\end{array}$ & Questionnaire & $\sqrt{ }$ & \\
\hline
\end{tabular}


Table 3. Cont.

\begin{tabular}{|c|c|c|c|c|}
\hline Variables & Instrument/Scale & Type of Assessment & 1st Phase & 2nd Phase \\
\hline Smoking history & $\begin{array}{l}\text { Self-reported as current or } \\
\text { ex-smoker/packs/year }\end{array}$ & Questionnaire & $\sqrt{ }$ & \\
\hline Alcohol consumption & $\begin{array}{l}\text { Self-reported as drinking or not alcohol } \\
\text { and units/week }\end{array}$ & Questionnaire & $\sqrt{ }$ & \\
\hline Social status & $\begin{array}{l}\text { Maastricht Social Participation Profile (MSSP), } \\
\text { Hospital Anxiety and Depression Scale (HADS) } \\
\text { Six-item Lubben Social Network }\end{array}$ & Questionnaire & & $\sqrt{ }$ \\
\hline Social isolation/loneliness & $\begin{array}{l}\text { Scale (LSNS-6), } \\
\text { De Jong Gierveld Short Loneliness Scale }\end{array}$ & Questionnaire & & $\sqrt{ }$ \\
\hline Occupation history & Self-reported current or previous employments & Questionnaire & & $\sqrt{ }$ \\
\hline Medical history/comorbidities & $\begin{array}{l}\text { Self-recorded list of current regular medications } \\
\text { including anti-osteoporosis medications }\end{array}$ & Questionnaire & $\sqrt{ }$ & \\
\hline Number of medications & $\begin{array}{l}\text { List of medical conditions provided used } \\
\text { previously in HCS study }\end{array}$ & Questionnaire & $\sqrt{ }$ & \\
\hline COVID-19 status & $\begin{array}{l}\text { COVID-19 questionnaire developed during the } \\
\text { pandemic and used previously in the HCS } \\
\text { study. Assess COVID-19 infection status and } \\
\text { symptomatology/long-term consequences; } \\
\text { COVID-19 vaccination status }\end{array}$ & Questionnaire & $\sqrt{ }$ & \\
\hline Physical activity & Physical Activity Scale for the Elderly (PASE) & Questionnaire & $\sqrt{ }$ & \\
\hline Physical capability & Self-reported walking speed & Questionnaire & $\sqrt{ }$ & \\
\hline \multirow{2}{*}{ Frailty } & Fried frailty criteria & $\begin{array}{l}\text { Questionnaire and } \\
\text { research visit }\end{array}$ & $\sqrt{ }$ & $\sqrt{ }$ \\
\hline & $\begin{array}{l}\text { Clinical frailty scale } \\
\text { Frailty index }(\mathrm{eFI})\end{array}$ & $\begin{array}{l}\text { Research visit } \\
\text { Research visit }\end{array}$ & & $\sqrt{ }$ \\
\hline \multirow{3}{*}{ Fractures/falls } & Self-reported number of fractures since the age & & & \\
\hline & $\begin{array}{l}\text { of } 45 \text { and in the past year } \\
\text { X-rays and vertebral fracture assessment }\end{array}$ & Questionnaire & $\sqrt{ }$ & \\
\hline & $\begin{array}{l}\text { Self-reported number of falls since the age of } 45 \\
\text { and in the past year }\end{array}$ & Questionnaire & $\sqrt{ }$ & \\
\hline \multirow{5}{*}{$\begin{array}{l}\text { Bone, muscle, fat: den- } \\
\text { sity/microarchitecture/morphology }\end{array}$} & $\begin{array}{l}\text { Strength, assistance with walking, rising from a } \\
\text { chair, climbing stairs, and falls (SARC-F) } \\
\text { Sarcopenia status (EWGSOP2) }\end{array}$ & Questionnaire & $\sqrt{ }$ & \\
\hline & DXA scan of lumbar spine and femoral neck & Research visit & & $\sqrt{ }$ \\
\hline & $\begin{array}{l}\text { High-resolution peripheral quantitative } \\
\text { computed tomography (HRpOCT) }\end{array}$ & Research visit & & $\sqrt{ }$ \\
\hline & Percutaneous muscle biopsy of vastus lateralis & Research visit & & $\sqrt{ }$ \\
\hline & Muscle ultrasound & Research visit & & $\sqrt{ }$ \\
\hline Perceived health state & $\begin{array}{c}\text { SF-36 } \\
\text { SarQoL (sarcopenia and quality of life) }\end{array}$ & Questionnaire & $\sqrt{ }$ & \\
\hline \multirow[t]{2}{*}{ Nutrition } & $\begin{array}{l}\text { DETERMINE checklist—identifying } \\
\text { malnutrition }\end{array}$ & Questionnaire & $\sqrt{ }$ & \\
\hline & $\begin{array}{l}\text { Food frequency questionnaire-assessing } \\
\text { habitual diet }\end{array}$ & Questionnaire & $\sqrt{ }$ & \\
\hline \multirow{3}{*}{ Anthropometric measurements } & $\begin{array}{l}\text { Weight, height, BMI, waist, hip, mid-upper } \\
\text { arm, and thigh circumferences }\end{array}$ & Research visit & & $\sqrt{ }$ \\
\hline & $\begin{array}{l}\text { Triceps, biceps, subscapular, and supra-iliac } \\
\text { skinfold thicknesses }\end{array}$ & Research visit & & $\sqrt{ }$ \\
\hline & Blood pressure, pulse rate & Research visit & & $\sqrt{ }$ \\
\hline Cardiovascular assessment & Standard 12-lead electrocardiograph & Research visit & & $\sqrt{ }$ \\
\hline Blood profile & $\begin{array}{l}\text { Fasting blood samples to be taken from the } \\
\text { anterior cubital fossa for subsequent glucose, } \\
\text { insulin, HbA1c, bone profile, albumin, lipid } \\
\text { profile, vitamin D, vitamin C, hormonal, } \\
\text { inflammatory, and DNA analyses, for posterity } \\
\text { and further assays; }\end{array}$ & Research visit & & $\sqrt{ }$ \\
\hline Physical performance & $\begin{array}{c}\text { Grip strength (Jamar hand-grip dynamometer) } \\
\text { Quadriceps strength } \\
\text { Timed } 6 \mathrm{~m} \text { up-and-go test and } 3 \mathrm{~m} \text { walk } \\
\text { Chair rises } \\
\text { Timed one-legged stand }\end{array}$ & Research visit & & $\sqrt{ }$ \\
\hline Cognitive function & AMTS $^{1} / \mathrm{MoCA}^{2}$ & Research visit & & $\sqrt{ }$ \\
\hline
\end{tabular}

${ }^{1}$ Abbreviated mental test score; ${ }^{2}$ Montreal Cognitive Assessment. 


\section{Patient and Public Involvement (PPI)}

Key to the success of SaLSA will be PPI. A research team member attended a virtual patient and public coffee morning meeting organised by the Patient and Public Group (PPG) of LWP. PPG representatives highlighted the importance of making sure that we ask the potential participants about their willingness to attend a future clinic, and advised that patients need to be seen in a "COVID-19-safe environment". We are continuing our engagement with the PPG group during the next phases of the study, in order to understand what COVID-19 mitigations would be required for participants to feel safe.

\section{Data Access}

A steering committee will be established to review all data access requests in due course. It will not be possible for participants to be identified from any of the statistical analysis outputs/results.

\section{Results}

\section{Preliminary Sample}

In total, 1993 participants were invited to participate, by post only; 450 (22.5\%) participants returned a questionnaire; 353 (79\%) questionnaires were complete; 295 participants $(84 \%)$ said they were happy to be contacted again to participate in future studies, while $35(10 \%)$ were not sure.

The summarised demographics of participants who returned the first 175 questionnaires are presented in Table 1 . The median age of participants was 80.4 (77-83) years in both sexes (80.5 years (77.9-84) in females and 80.4 years in males (77.3-83.6)). The majority ( $\mathrm{N}=168 / 171,98 \%$ ) of participants were of white ethnic background. Two (2) females of Indian origin and one (1) female of Black Caribbean origin were included. In total, 36/53 (68\%) female participants and 38/119 (32\%) male participants live alone; $152 / 171$ participants left school over the age of 14 (50/52 females and 102/119 males). Over half of female participants (28/52 (53\%)), and 86/119 (72\%) male participants continued with education after school; 29/54 female and 78/121 male participants obtained a higher qualification degree; $58 \%(98 / 171)$ of participants are ex-smokers, and only $5 / 171$ still smoke, all of whom are males (3\%). Only $1 / 54$ of females and 25/121 of male participants who drink alcohol consume more than the recommended units/week (14 UI/week). Only $2 / 50(4 \%)$ females suspect that they have had COVID-19, and 4/117 (2\%) male participants had confirmed COVID-19 infection.

Over $70 \%$ of female and male participants $(n=149 / 175)$ reported having $>=2$ comorbidities, and so would fulfil the definition of multimorbidity. Over $60 \%$ of female participants $(33 / 53)$ reported polypharmacy, defined as $>=5$ regular medications, compared to $18 \%(22 / 117)$ of male participants. Walking speed was self-reported by all participants. Around onethird of participants self-reported walking at a normal speed (13/54 (24\%) females and $40 / 121(33 \%)$ males) and strolling at an easy pace (15/54 (28\%) females and 34/121 (28\%)) in both sexes.

One-third of female participants $(17 / 52)$ and one-quarter of male participants $(28 / 114)$ reported at least one fall in the past year. One-third of all participants (19/52 and 15/112 female and male participants, respectively) reported a fracture since the age of 45 .

Most participants rated their health to be "good" (70/175 (40\%)). Their health was rated as "fair" in 28\% (49/175) and "very good" in 23\% of participants in both sexes (40/175). Only $4 \%$ self-rated their health as "excellent" (7/175) or "poor" (7/175) in this cohort.

We have previously studied the impact of the COVID-19 pandemic on participants in the HCS. We were therefore interested to understand how comparable the two cohorts were. Participants recruited in the SaLSA and NAPA studies were septuagenarians and octogenarians (Median age (IQR) in females: 80.5 (77-84)) and 83.8 (81.5-85.9) years, respectively; and in males: 80.4 (77-83) and 83.1 (81.5-85.5) years, respectively). Polypharmacy was common in both cohorts (the median number of medications used was 5 in females in both the NAPA and SaLSA studies, and in males in the NAPA study). Most female participants 
in SaLSA live alone (68\%), whereas in NAPA less than half of female participants reported living alone (45.1\%).

\section{Discussion}

Musculoskeletal conditions such as osteoporosis and sarcopenia are a public health burden, and treatment strategies, including the development of novel therapeutic targets, are urgently required. This manuscript reports the first stages in establishing a new resource for the study of musculoskeletal health, which began at the time of a global pandemic, when many older adults experienced significant disruptions to their lifestyles as a result of public health messages designed to protect them from the risk of COVID-19 infection. The work is indicated now as there is an even greater need to consider musculoskeletal health in this group. Currently, it is uncertain whether these lifestyle changes will be reversible, in the context of widespread vaccination. Previous research in the HCS and elsewhere has shown that lifestyle risk factors cluster together to impact on physical function in later life, and contribute to the progression of sarcopenia, osteoporosis, and/or osteoarthritis, so information on this topic is urgently required [23].

A particular challenge of this work has been its initiation while the pandemic is ongoing. Recruitment of community participants for clinical research studies is often a challenging task. SaLSA is unique, as it will enable the assessment of the feasibility and practicality of recruiting older adults from the community who are likely research-naïve; it will establish a platform for future observational and interventional studies to identify at-risk groups or normal ageing participants. The cohort data will enable the development and evaluation of interventions targeted at improving health care outcomes for older adults. Specifically, data will be used to identify at-risk groups such as those suffering from osteoporosis, sarcopenia, osteosarcopenia, and/or frailty.

There has recently been growing interest in the coexistence of osteoporosis and sarcopenia in some individuals, often termed osteosarcopenia. There appears to be higher morbidity from falls, fractures, disability, and mortality in individuals diagnosed with osteosarcopenia $[12,28]$. However, there are limited epidemiological data on the subject, and more work is needed in order to understand the interrelationships between the two conditions. Specifically, knowledge of the overlap in the pathophysiology of osteoporosis and sarcopenia might inform the development of potential treatments for osteosarcopenia [29]. A variety of physical assessments is at the clinician's disposal when assessing for osteosarcopenia, and will be assessed in this study. The choice of physical assessment(s) is largely dependent on the clinician's preferred definition of sarcopenia. The two most useful physical assessments are the measurement of hand grip strength $(\mathrm{kg})$ using a handheld dynamometer, and calculation of walking speed $(\mathrm{m} / \mathrm{s})$ over $4 \mathrm{~m}$, as per the European Working Group on Sarcopenia in Older Adults (EWSGOP2) [4].

An exciting area of sub-study is in-depth muscle and bone phenotyping. We have previously studied muscle-bone interrelationships in the HCS [30,31], but SaLSA provides an opportunity to perform detailed investigation of bone trabecular and cortical microarchitecture using HRpQCT [32-36], muscle ultrasound [24], and muscle biopsy-a technique which we have previously shown to be acceptable to older adults [27]. These studies are critical, as muscle-bone crosstalk is an important and emerging area of research. Genetic, mechanical, and endocrine factors may explain the age-related association between muscle and bone loss [37]. There is accumulating evidence that other localized and systemic factors are involved, including mesenchymal stem cells residing in connective tissue (muscle, bone, and fat), myokines and osteokines (molecules released from muscle and bone cells, respectively), inflamm-ageing, and fat infiltration [38]. These pathophysiological findings are common to both sarcopenia and osteoporosis, thus suggesting that the two are closely linked [39].

There are, of course, limitations to our study, including the low number of nonCaucasian participants currently recruited, and our decision to exclude residential and nursing home residents, which might affect the implementation of our results to this group 
of older adults. We will consider the characteristics of our study population against national census data at the conclusion of phase 1 of this study. However, the strengths of the study include a strong collaboration with LWP and their PPG group, supported by an experienced team of multidisciplinary team of researchers from the MRC LEC.

\section{Conclusions}

We have demonstrated that the recruitment of participants from primary care is feasible, with high levels of consent to contact for future study to establish a longitudinal study of ageing. Through SaLSA, we aim to study bone-muscle interrelationships in depth, and to provide an opportunity to collaborate with other researchers working in similar cohorts globally. Other future sub-studies could also explore determinants related to healthy ageing, including relevant psychosocial factors such as isolation, attitudes to ageing, social networks, satisfaction with life. and many more. In addition, having an interdisciplinary team of investigators encourages collaboration, and enables the introduction of in-depth and novel health assessments contributing to generating novel ideas for future research, allowing comparison with other cohorts such as the HCS. SaLSA will also promote training opportunities for both quantitative and qualitative early-career researchers. Adopting a community-based recruitment strategy will enable efficient coordination of activities between researchers in universities, secondary care establishments, and the community. SaLSA will set an example, enabling the establishment of a unique community-dwelling cohort, and in time we hope it will provide clinicians, researchers, and policymakers with a rich resource for further collaborative study, with the ultimate aim of improving health care for our local community-dwelling older people.

Author Contributions: Conceptualization, F.L., E.M.D. and H.P.P.; methodology, F.L., P.A., E.M.D. and H.P.P.; formal analysis, F.L.; data curation, F.L. and A.L.; writing-original draft preparation, F.L.; writing-review and editing, F.L., A.L., P.A., E.M.D. and H.P.P. All authors have read and agreed to the published version of the manuscript.

Funding: F.L. and H.P.P. are supported by the NIHR Southampton Biomedical Research Centre, Nutrition, and the University of Southampton. This report is independent research, and the views expressed in this publication are those of the authors, and not necessarily those of the NHS, the NIHR, or the Department of Health. These funding bodies had no role in the writing of the manuscript or the decision to submit it for publication.

Institutional Review Board Statement: This study was conducted according to the guidelines of the Declaration of Helsinki, and approved by the Research Ethics Committee (REC) Health Regulator Authority (HRA) (REC reference 21/SC/0036, 17 March 2021).

Informed Consent Statement: Informed consent was obtained from all subjects involved in the study.

Data Availability Statement: The data presented in this study are available on request from the corresponding author. The data are not publicly available due to ethical restrictions (REC reference 21/SC /0036, 17 March 2021). Data are collected and retained in accordance with the Data Protection Act 1998 (GDPR from May 2018). All study data are anonymised from the initial data collection stage. Study data are stored on a password-protected computer held at the MRC LEU which is operated by a designated data protection officer.

Conflicts of Interest: F.L., A.L. and P.A. have nothing to declare. H.P.P. has received lecture fees from Abbott, Pfizer, and HC-UK conferences outside of the submitted work. E.D. declares consultancy and speaker fees from Pfizer, UCB, and Lilly.

\section{References}

1. Johnell, O.; Kanis, J.A. An estimate of the worldwide prevalence and disability associated with osteoporotic fractures. Osteoporos. Int. 2006, 17, 1726-1733. [CrossRef] [PubMed]

2. Barnsley, J.; Buckland, G.; Chan, P.E.; Ong, A.; Ramos, A.S.; Baxter, M.; Laskou, F.; Dennison, E.M.; Cooper, C.; Patel, H.P. Pathophysiology and treatment of osteoporosis: Challenges for clinical practice in older people. Aging Clin. Exp. Res. 2021, 33, 759-773. [CrossRef] [PubMed]

3. Rosenberg, I.H. Sarcopenia: Origins and clinical relevance. Clin. Geriatr. Med. 2011, 27, 337-339. [CrossRef] 
4. Cruz-Jentoft, A.J.; Bahat, G.; Bauer, J.; Boirie, Y.; Bruyère, O.; Cederholm, T.; Cooper, C.; Landi, F.; Rolland, Y.; Sayer, A.A.; et al. Sarcopenia: Revised European consensus on definition and diagnosis. Age Ageing 2019, 48, 16-31. [CrossRef]

5. Oliveira, A.; Vaz, C. The role of sarcopenia in the risk of osteoporotic hip fracture. Clin. Rheumatol. 2015, 34, 1673-1680. [CrossRef] [PubMed]

6. Janssen, I.; Shepard, D.S.; Katzmarzyk, P.T.; Roubenoff, R. The Healthcare Costs of Sarcopenia in the United States. J. Am. Geriatr. Soc. 2004, 52, 80-85. [CrossRef]

7. Pinedo-Villanueva, R.; Westbury, L.D.; Syddall, H.E.; Sanchez-Santos, M.T.; Dennison, E.M.; Robinson, S.M.; Cooper, C. Health Care Costs Associated With Muscle Weakness: A UK Population-Based Estimate. Calcif. Tissue Int. 2019, 104, 137-144. [CrossRef]

8. Cawthon, P.M.; Manini, T.; Patel, S.M.; Newman, A.; Travison, T.; Kiel, D.P.; Santanasto, A.J.; Ensrud, K.E.; Xue, Q.L.; Shardell, M.; et al. Putative Cut-Points in Sarcopenia Components and Incident Adverse Health Outcomes: An SDOC Analysis. J. Am. Geriatr. Soc. 2020, 68, 1429-1437. [CrossRef]

9. $\quad$ Studenski, S.A.; Peters, K.W.; Alley, D.E.; Cawthon, P.M.; McLean, R.R.; Harris, T.B.; Ferrucci, L.; Guralnik, J.M.; Fragala, M.S.; Kenny, A.M.; et al. The FNIH sarcopenia project: Rationale, study description, conference recommendations, and final estimates. J. Gerontol. Ser. A Biol. Sci. Med. Sci. 2014, 69, 547-558. [CrossRef]

10. Chen, L.K.; Woo, J.; Assantachai, P.; Auyeung, T.W.; Chou, M.Y.; Iijima, K.; Jang, H.C.; Kang, L.; Kim, M.; Kim, S.; et al. Asian Working Group for Sarcopenia: 2019 Consensus Update on Sarcopenia Diagnosis and Treatment. J. Am. Med. Dir. Assoc. 2020, 21, 300-307.e2. [CrossRef]

11. Curtis, E.; Litwic, A.; Cooper, C.; Dennison, E. Determinants of Muscle and Bone Aging. J. Cell. Physiol. 2015, 230, 2618-2625. [CrossRef] [PubMed]

12. Huo, Y.R.; Suriyaarachchi, P.; Gomez, F.; Curcio, C.L.; Boersma, D.; Muir, S.W.; Montero-Odasso, M.; Gunawardene, P.; Demontiero, O.; Duque, G. Phenotype of Osteosarcopenia in Older Individuals With a History of Falling. J. Am. Med. Dir. Assoc. 2015, 16, 290-295. [CrossRef]

13. Hill, T.R.; Aspray, T.J. The role of vitamin D in maintaining bone health in older people. Ther. Adv. Musculoskelet. Dis. 2017, 9, 89-95. [CrossRef] [PubMed]

14. Bischoff-Ferrari, H.A.; Dawson-Hughes, B.; Stöcklin, E.; Sidelnikov, E.; Willett, W.C.; Edel, J.O.; Stähelin, H.B.; Wolfram, S.; Jetter, A.; Schwager, J.; et al. Oral supplementation with 25(OH)D3 versus vitamin D3: Effects on 25(OH)D levels, lower extremity function, blood pressure, and markers of innate immunity. J. Bone Miner. Res. 2012, 27, 160-169. [CrossRef] [PubMed]

15. Dennison, E. Assessment of How Older Adults Have Been Affected by COVID-19: A Look at the Hertfordshire Cohort StudyCLOSER. 2020. Available online: https:/ /www.closer.ac.uk/news-opinion/blog/assessment-of-how-older-adults-have-beenaffected/ (accessed on 26 October 2021).

16. Han, M.F.Y.; Mahendran, R.; Yu, J. Associations Between Fear of COVID-19, Affective Symptoms and Risk Perception Among Community-Dwelling Older Adults During a COVID-19 Lockdown. Front. Psychol. 2021, 12, 961. [CrossRef]

17. Washburn, R.A.; McAuley, E.; Katula, J.; Mihalko, S.L.; Boileau, R.A. The Physical Activity Scale for the Elderly (PASE): Evidence for Validity. J. Clin. Epidemiol. 1999, 52, 643-651. [CrossRef]

18. Sinnett, S.; Bengle, R.; Brown, A.; Glass, A.P.; Johnson, M.A.; Lee, J.S. The validity of nutrition screening initiative DETERMINE Checklist responses in older Georgians. J. Nutr. Elder. 2010, 29, 393-409. [CrossRef]

19. Mchorney, C.A.; Johne, W.; Anastasiae, R. The MOS 36-Item Short-Form Health Survey (SF-36). Med. Care 1993, 31, $247-263$. [CrossRef]

20. Bingham, S.A.; Gill, C.; Welch, A.; Day, K.; Cassidy, A.; Khaw, K.T.; Sneyd, M.J.; Key, T.J.A.; Roe, L.; Day, N.E. Comparison of dietary assessment methods in nutritional epidemiology: Weighed records v. $24 \mathrm{~h}$ recalls, food-frequency questionnaires and estimated-diet records. Br. J. Nutr. 1994, 72, 619-643. [CrossRef]

21. Syddall, H.E.; Westbury, L.D.; Cooper, C.; Sayer, A.A. Self-Reported Walking Speed: A Useful Marker of Physical Performance Among Community-Dwelling Older People? J. Am. Med. Dir. Assoc. 2015, 16, 323-328. [CrossRef]

22. Malmstrom, T.K.; Morley, J.E. SARC-F: A simple questionnaire to rapidly diagnose sarcopenia. J. Am. Med. Dir. Assoc. 2013, 14, 531-532. [CrossRef] [PubMed]

23. Syddall, H.E.; Simmonds, S.J.; Carter, S.A.; Robinson, S.M.; Dennison, E.M.; Cooper, C.; Bevilacqua, G.; Bloom, I.; Clynes, M.; Cox, K.; et al. The hertfordshire cohort study: An overview [version 1; referees: 3 approved]. F1000Research 2019, 8, 82. [CrossRef] [PubMed]

24. Perkisas, S.; Bastijns, S.; Baudry, S.; Bauer, J.; Beaudart, C.; Beckwée, D.; Cruz-Jentoft, A.; Gasowski, J.; Hobbelen, H.; JagerWittenaar, H.; et al. Application of ultrasound for muscle assessment in sarcopenia: 2020 SARCUS update. Eur. Geriatr. Med. 2021, 12, 18. [CrossRef] [PubMed]

25. Westbury, L.D.; Dodds, R.M.; Syddall, H.E.; Baczynska, A.M.; Shaw, S.C.; Dennison, E.M.; Roberts, H.C.; Sayer, A.A.; Cooper, C.; Patel, H.P. Associations Between Objectively Measured Physical Activity, Body Composition and Sarcopenia: Findings from the Hertfordshire Sarcopenia Study (HSS). Calcif. Tissue Int. 2018, 103, 237. [CrossRef]

26. Sample Size Calculator. Statistics Kingdom, 2017. Available online: https://www.statskingdom.com/sample_size_all.html (accessed on 26 October 2021).

27. Patel, H.P.; Syddall, H.E.; Martin, H.J.; Stewart, C.E.; Cooper, C.; Sayer, A.A. Hertfordshire sarcopenia study: Design and methods. BMC Geriatr. 2010, 10, 43. [CrossRef] [PubMed] 
28. Cevei, M.; Onofrei, R.R.; Cioara, F.; Stoicanescu, D. Correlations between the Quality of Life Domains and Clinical Variables in Sarcopenic Osteoporotic Postmenopausal Women. J. Clin. Med. 2020, 9, 441. [CrossRef] [PubMed]

29. Paintin, J.; Cooper, C.; Dennison, E. Osteosarcopenia. Proc. Br. J. Hosp. Med. 2018, 79, 253-258. [CrossRef]

30. Patel, H.P.; Dawson, A.; Westbury, L.D.; Hasnaoui, G.; Syddall, H.E.; Shaw, S.; Sayer, A.A.; Cooper, C.; Dennison, E.M. Muscle Mass, Muscle Morphology and Bone Health Among Community-Dwelling Older Men: Findings from the Hertfordshire Sarcopenia Study (HSS). Calcif. Tissue Int. 2018, 103, 35. [CrossRef]

31. Edwards, M.H.; Gregson, C.L.; Patel, H.P.; Jameson, K.A.; Harvey, N.C.; Sayer, A.A.; Dennison, E.M.; Cooper, C. Muscle size, strength, and physical performance and their associations with bone structure in the Hertfordshire Cohort Study. J. Bone Miner. Res. 2013, 28, 2295-2304. [CrossRef]

32. Boutroy, S.; Bouxsein, M.L.; Munoz, F.; Delmas, P.D. In vivo assessment of trabecular bone microarchitecture by high-resolution peripheral quantitative computed tomography. J. Clin. Endocrinol. Metab. 2005, 90, 6508-6515. [CrossRef]

33. Sornay-Rendu, E.; Boutroy, S.; Munoz, F.; Delmas, P.D. Alterations of cortical and trabecular architecture are associated with fractures in postmenopausal women, partially independent of decreased BMD measured by DXA: The OFELY study. J. Bone Miner. Res. 2007, 22, 425-433. [CrossRef] [PubMed]

34. Edwards, M.; Robinson, D.; Ward, K.; Javaid, M.; Walker-Bone, K.; Cooper, C.; Dennison, E. Cluster Analysis of Bone Microarchitecture from High Resolution Peripheral Quantitative Computed Tomography Demonstrates two Separate Phenotypes Associated with High Fracture Risk in Men and Women. Bone 2016, 88, 131. [CrossRef] [PubMed]

35. Stein, E.M.; Liu, X.S.; Nickolas, T.L.; Cohen, A.; Thomas, V.; McMahon, D.J.; Zhang, C.; Yin, P.T.; Cosman, F.; Nieves, J.; et al. Abnormal Microarchitecture and Reduced Stiffness at the Radius and Tibia in Postmenopausal Women With Fractures. J. Bone Miner. Res. 2010, 25, 2572. [CrossRef] [PubMed]

36. Litwic, A.E.; Westbury, L.D.; Robinson, D.E.; Ward, K.A.; Cooper, C.; Dennison, E.M. Bone Phenotype Assessed by HRpQCT and Associations with Fracture Risk in the GLOW Study. Calcif. Tissue Int. 2018, 102, 14. [CrossRef] [PubMed]

37. Kirk, B.; Zanker, J.; Duque, G. Osteosarcopenia: Epidemiology, diagnosis, and treatment-Facts and numbers. J. Cachexia. Sarcopenia Muscle 2020, 11, 609-618. [CrossRef] [PubMed]

38. Laskou, F.; Patel, H.P.; Cooper, C.; Dennison, E. A pas de deux of osteoporosis and sarcopenia: Osteosarcopenia. Climacteric 2022, 25, 88-95. [CrossRef]

39. Hirschfeld, H.P.; Kinsella, R.; Duque, G. Osteosarcopenia: Where bone, muscle, and fat collide. Osteoporos. Int. 2017, 28, 2781-2790. [CrossRef] 